OPEN ACCESS

Edited by: Gaowei Chen,

The University of Hong Kong, China

Reviewed by: Jiahong Zhang,

University of Wisconsin-Madison, United States Sündüs Yerdelen, Kafkas University, Turkey

*Correspondence: Sammy K. Ho sammyho@hkbu.edu.hk

Specialty section:

This article was submitted to Educational Psychology, a section of the journal

Frontiers in Education

Received: 06 March 2021 Accepted: 26 May 2021 Published: 10 June 2021

Citation: Ho SK, Chan H, Chan ES-S, Fung K-K and Hung SS-L (2021) A Preliminary Psychometric Investigation of a Chinese Version of the Engaged

Teachers Scale (C-ETS).

Front. Educ. 6:676835.

doi: $10.3389 /$ feduc.2021.676835

\section{A Preliminary Psychometric Investigation of a Chinese Version of the Engaged Teachers Scale (C-ETS)}

\author{
Sammy K. Ho ${ }^{1 *}$, Hang Chan ${ }^{1}$, Edmund Sze-Shing Chan ${ }^{2}$, Kwok-Kin Fung ${ }^{3}$ and \\ Shirley Suet-Lin Hung ${ }^{3}$
}

${ }^{1}$ Department of Education Studies, Faculty of Social Sciences, Hong Kong Baptist University, Hong Kong, China, ${ }^{2}$ Faculty of Social Sciences and Education, University of Saint Joseph, Macau, China, ${ }^{3}$ Department of Social Work, Faculty of Social Sciences, Hong Kong Baptist University, Hong Kong, China

This study examines the psychometric properties of a Chinese version of the Engaged Teacher Scale (C-ETS). A translated questionnaire with 16 items was administered to a sample of 341 primary and secondary school teachers in Hong Kong. A series of confirmatory factor analyses were performed to assess the construct, convergent, and discriminant validity of the scale in alternative models. Results provide support for a second-order model with teacher engagement as an overarching construct with four hypothesized dimensions: emotional engagement, cognitive engagement, social engagement (students), and social engagement (colleagues). The C-ETS provides a useful measure for teacher engagement in Chinese societies. Contributions and limitations of the study are discussed.

Keywords: teacher engagement, confirmatory factor analyses, school teachers, psychometrics, validation

\section{INTRODUCTION}

In the last 2 decades, organizational researchers have shifted their focus from the negative states of burnout, such as extreme fatigue (exhaustion), distancing from work and people (cynicism), and the loss of idealism and passion for one's job (reduced professional efficacy), to the positive antithesis of burnout, that is, one's engagement with their work which often involve energy (feeling energetic at work), involvement (establishing an enthusiastic attitude toward the job), and efficacy (feeling capable of one's productivity at work) (Maslach et al., 2001). According to Maslach et al. (2001), engagement represents the positive end of a bipolar scale and burnout represents the negative end. Based on this description, engagement is simply assessed by using the opposite pattern of scores on the three burnout dimensions (exhaustion vis-à-vis energy; cynicism vis-à-vis involvement; reduced professional efficacy vis-à-vis efficacy).

Schaufeli and colleagues (Schaufeli et al., 2002; Schaufeli and Bakker, 2004; Bakker et al., 2007; Bakker et al., 2008), however, take a different approach to the concept of engagement. They argue engagement should not be simply assessed by the reversed scores of the burnout profile. For example, feeling emotionally exhausted from one's work "once a week" does not necessarily excludes the possibility that an individual may feel full of energy in the same week. It is because the burnout scale can sometimes fail to capture positive experiences associated with engagement (Bakker et al., 2007; Maslach et al., 2008). They further posit that the concepts of burnout and engagement are independent yet negatively correlated with each other. Engagement is more than energy, involvement, and efficacy (Maslach et al., 2008). Engagement is thus redefined as "a persistent, positive affective-motivational state of fulfillment that is characterized by the three components of 
vigor, dedication, and absorption" (Maslach et al., 2008, p.103). Vigor is described as high levels of energy, mental resilience, and willingness to invest energy of a worker. Dedication is characterized by an individual's strong enthusiasm and persistence in one's work even facing difficulties and challenges. Finally, absorption refers to being fully immersed in one's work to the extent that an individual is unable to detach oneself from work with a distortion of time. Based on this conception of engagement, Schaufeli and colleagues have developed the well-known Utrecht Work Engagement Scale (UWES) to measure the three components of engagement (Schaufeli et al., 2002; Schaufeli and Bakker, 2004). There are 17 items in the scale (UWES-17), and a brief version consists of nine items (UWES-9) evenly covering each of the three engagement factors (Schaufeli et al., 2006). The UWES-17 and UWES-9 have shown sound psychometric properties in various research studies (e.g. Schaufeli et al., 2002; González-Romá et al., 2006; Schaufeli et al., 2006).

\section{Teacher Engagement}

Based on the Self-Determination Theory (SDT) Deci and Ryan. (1985), work engagement reflects intrinsic and autonomous motivation that have been shown to contribute to higher levels of performance and persistence Meyer and Gagné. (2008). As such, engaged teachers are more likely to find teaching interesting and funny, and derive spontaneous satisfaction from teaching itself wholly volitionally. With the conceptual shift of focusing from burnout to engagement, teacher engagement has gained burgeoning interest in educational research recently. For example, research using the UWES demonstrates that teacher engagement was positively correlated with the teachers' job satisfaction and negatively correlated with their intention to leave the job (Høigaard et al., 2012; Klassen et al., 2012; Eldor and Shoshani, 2017). Engaged teachers were more likely to perform better in their jobs Bakker and Bal. (2010) and commit to their schools (Hakanen et al., 2006; Jackson et al., 2006). Teachers with high levels of engagement employed less effort in emotional labor, (i.e. regulation and suppression of emotional feelings to behave in certain ways) to deal with the emotional demands of their profession Philipp and Schüpbach. (2010), and suffered less from physical and psychological illhealth (Hakanen et al., 2006; Jackson et al., 2006; Timms et al., 2007; Barkhuizen et al., 2013). Individual differences are also found in teacher engagement research. For example, teachers who scored high in self-efficacy were more engaged at work (Høigaard et al., 2012; Skaalvik and Skaalvik, 2014; Lu et al., 2018).

Notwithstanding teacher engagement has been found to be related to a number of teacher attributes and outcomes, few studies have actually attempted to confirm the proposed threefactor solution of the UWES in measuring teacher engagement. In an attempt to validate the psychometric properties of the UWES involving teacher informants across five countries, Klassen et al. (2012) found that the one-factor model of the UWES was superior to the three-factor model with vigor, dedication, and absorption in fit. High correlations among the three factors were found and the three-factor structure of the scale was not invariance across settings, showing that a further modification of the scale was required. Han et al. (2016) also found more support for the one-factor model over the three-factor model of the UWES in a sample of Chinese tertiary teachers. Another problem of using the UWES to measure teacher engagement is that it is not a context-specific tool that may fail to gauge the unique job nature of teaching (Klassen et al., 2012). Since the UWES may fail to reflect some work performed by teachers at school that often involves extensive interpersonal interactions both inside and outside the classroom, (e.g. an extensive energy devoted to establishing long-term relationships with students and colleagues), there is a room for development of a new engagement scale for teachers. Focusing on the connection with students and colleagues fits well with a teacher's need of relatedness-an inherent psychological mechanism within the SDT (Gagné and Deci, 2005). Drawing on the SDT, work provides individuals with the opportunities to satisfy the needs to be connected with other people, which is essential to the development of work engagement.

\section{Engaged Teacher Scale}

Built upon the UWES, a brief multidimensional scale of teacher engagement-the Engaged Teacher Scale (ETS) was developed by Klassen et al. (2013) to capture the unique job-related context and demands experienced by teachers. Klassen et al. (2013) created and validated the ETS in English through five steps with different samples. Initially, a pool of items was generated based on the current work engagement theory and measures. Then a pilot study was conducted and the number of items was reduced. In the second step, the scale was subjected to principal component analysis (PCA) for item reduction purposes. Eventually 27 items were left for the third step of analysis. In step 3, factorial validity of the 27 -item scale was assessed by explanatory factor analysis (EFA), screen plot test, and parallel analysis. Items with low factor pattern coefficients and redundant content were further removed, leaving a 16-item scale with four items in each of the four dimensions of engagement, including emotional, cognitive, social: students, and social: colleagues. The emotional dimension is closely allied to the dedication dimension and the cognitive dimension is germane to the vigor and absorption dimensions of the UWES. Specifically, emotional engagement reflects enthusiasm, inspiration, and pride in teaching. Cognitive engagement refers to concentration, resilience, and teachers' investment of energy and mental resources in their work. Social engagement with students and colleagues denotes teachers' energy devoted to connect with students and colleagues, respectively. In step 4 , a series of first- and second-order confirmatory factor analyses (CFAs) were carried out to examine the construct validity of the 16 -item scale. The goodness-of-fit indices showed that both the first and second-order models fitted well to the data, indicating that both the factor scores and the composite score of the scale can measure teacher engagement. In the fifth and final step, convergent validity of the ETS was assessed by canonical correlation analyses with the Teacher Sense of Efficacy Scale (TSES) and the UWES. Results suggested positive relationships between all teacher engagement factors and the subscales of 
TSES and UTWS, and thus the convergent validity of the ETS was supported.

To examine the cultural relevancy of the ETS, Yerdelen et al. (2018) investigated the psychometric properties of the scale in a Turkish context (ETS-TR). A total of 388 teachers completed the ETS-TR. Results showed good fit to the data of the Turkish version of the scale in both the first-order (four-factor) and second-order (a superordinate factor) CFA, supporting the construct validity of the scale. The overall alpha coefficient for the ETS-TR was 0.88 , and the subscale alphas ranged from 0.81 to 0.87 , indicating that the scores on the ETS-TR were reliable. Significant bivariate correlations among subscale scores of ETSTR and TSES supported the convergent validity of the ETS-TR. In particular teachers who reported a higher level of efficacy in classroom management were more engaged in their work. Perera et al. (2018b) examined the dimensional structure of the ETS by means of both confirmatory factor analysis (CFA) and exploratory structural equation modeling (ESEM). Results showed that a bifactor-ESEM model, characterized by a general engagement and special engagement factors, provided the best fit to the data. However, item 15 "While teaching, I work with intensity" did not load well on its specific cognitive engagement factor but loaded high on the general engagement factor, indicating that the allocation of attentional resources is required across different domains in teaching. This measurement model was also found to be invariant across teaching level and time. Criterion validity of the EST was partially supported, with the general engagement factor, emotional engagement, and social engagement with colleagues positively related to later job satisfaction.

\section{Present Study}

The present study aims to validate a Chinese version of the Engaged Teacher Scale (C-ETS) that assesses four different domains of work engagement of teachers. In view of the fact that the currently existing Engaged Teacher Scale is only available in English and Turkish, there is a need to adapt this engagement scale for teachers in Chinese communities. The long-term contribution of the present study is that an understanding of the various aspects of teacher engagement can be enhanced by establishing a Chinese version of the existing ETS. Since teacher engagement is predictive of teacher effectiveness, student outcomes (e.g. achievement), and teacher outcomes, (e.g. their well-being and job stability) Klassen and Durksen (2015), a validated, reliable measure of teacher engagement will enable future researchers to understand the complex process of teaching and learning in classrooms and in schools (Klassen et al., 2013).

\section{METHODS}

\section{Procedures and Participants}

An invitation letter and a sample of the questionnaire packet were sent to 15 referred school principals for their approval of collection of data from their school teachers. Consent was obtained from 13 principals, hardcopies of the questionnaire with an acknowledgment letter were then sent to the schools.

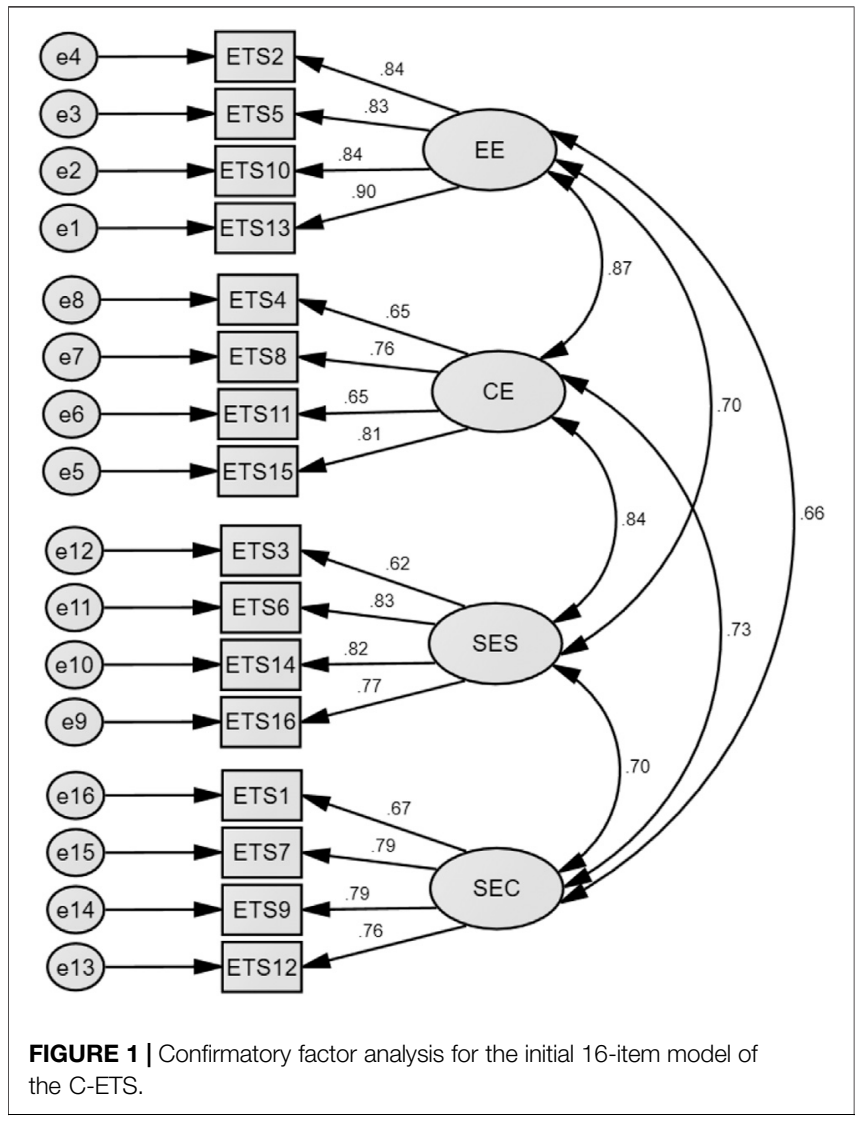

The team members of project collected the completed questionnaires in person. All questionnaires were completed by the teachers anonymously. About 600 questionnaires were sent to the schools, and 341 completed questionnaires were collected from 109 men and 231 women (one of them did not indicate his/her gender). Nearly $60 \%$ (202) of them worked in primary schools and about 40\% (138) of them worked in secondary schools (one of them did not indicate his/her level of school). The average teaching experience of them was 13.19 years, with a standard deviation of 9.24.

\section{Instrument}

The Engaged Teacher Scale is a 16-item scale that conceptually consists of four different dimensions of engagement: emotional engagement, cognitive engagement, social engagement-students, and social engagement-colleagues (Klassen et al., 2013). Participants rated each item based on a seven-point Likert scale, ranging from never (0) to always (6), with higher scores associated with higher level of engagement. It was translated into Chinese using traditional characters and back-translated into English by two independent bilingual translators working in the language center at a local university. The back-translated version was sent to the original author of the ETS for examination to ensure that the translated items were equivalent and faithful to the original wording. After receiving feedback from the ETS's author, minor revisions were made by another translator and the 
TABLE 1 | Convergent and discriminant validity of the initial 16-item model of C-ETS.

\begin{tabular}{lcccc}
\hline & AVE & EE & CE & SES \\
\hline Emotional engagement (EE) & 0.728 & - & & \\
Cognitive engagement (CE) & 0.520 & 0.757 & - & \\
Social engagement: students (SES) & 0.585 & 0.490 & 0.706 & - \\
Social engagement: colleagues (SEC) & 0.569 & 0.436 & 0.533 & 0.490
\end{tabular}

Note. AVE = Average variance extracted. Square of the correlations among the four factors of teacher engagement are off-diagonal, ps $<0.001$

first author with consensus. As such, the original and backtranslated versions were deemed to substantially equivalent and consistent in meaning.

\section{RESULTS}

\section{Construct Validity and Reliability}

Confirmatory factor analysis using maximum likelihood estimation with SPSS AMOS 25.0 was conducted to examine the construct validity of the initial four-factor model (emotional engagement, cognitive engagement, social engagement: students, and social engagement: colleagues) on the 16-item C-ETS (Figure 1). As in the English and Turkish versions of the ETS, all standardized loading estimates were significantly above the cut-off value of 0.5 Hair et al. (2018) and varied from 0.62 to 0.90 . To examine the fit of the model, various absolute and relative fit indices were evaluated, including the normed chi-square $\left(\chi^{2} / \mathrm{df}\right)$, Root Mean Square Error of Approximation (RMSEA), Comparative Fit Index (CFI), Normed Fit Index (NFI), Incremental Fit Index (IFI), and Tucker-Lewis Index (TLI). The value of chi-square divided by degree of freedom between two and five is considered as acceptable (Bollen, 1989). CFI and its associated indexes (NFI, IFI, and TLI) in the values above 0.95 and those of RMSEA below 0.07 suggest good level of fit (Browne and Cudeck, 1993; Hu and Bentler, 1999; Bryne, 2016). Upon checking various fit indices, the results showed that the fit between the data and model was only marginal $\left(\chi^{2} / \mathrm{df}=4.25\right.$, $p<0.001$; RMSEA $=0.098,90 \% \mathrm{CI}=0.088,0.108$; CFI $=0.91$; NFI $=0.89 ; \mathrm{IFI}=0.91$; and TLI $=0.89$ ). The reliability coefficients of emotional engagement, cognitive engagement, social engagement: students, and social engagement: colleagues were good, with Cronbach's alphas ranged from 0.81 to 0.91 .

\section{Convergent and Discriminant Validity}

Convergent validity refers to the extent to which a set of indicators can presume to measure a construct and discriminant validity assesses the level of construct which is different from one another (Kline, 2016). Average variance extracted (AVE) is calculated to measure the amount of variance shared by a set of indicators of a construct, with the value higher than 0.50 indicates adequate convergent validity of a construct (Hair et al., 2018). To assess discriminant validity, AVE estimates of each construct should be higher than the square of correlations with other constructs based on the Fornell and Larcker criterion (Hair et al., 2018). For example, both the values of AVE for constructs A and B should be greater than the square of the correlation (shared variance) between them. The equation of AVE can be illustrated as: $\Sigma \lambda^{2} / k$, where $\lambda$ represents standardized loading of each indicator and $k$ represents the number of indicators of each construct. AVE is calculated as the sum of square of the standardized factor loading of each indicator divided by the number of indicators each construct has. As shown in Table 1, all the AVE values exceeded 0.50, providing evidence of convergent validity of the four factors of C-ETS. However, discriminant validity among the four factors was insufficient. For example, the AVE values of EE (0.728) and CE (0.520) were smaller than their square of the correlation (= 0.757), indicating that the two factors were not distinct well from each other. This result was not surprising, as previous research has shown that the correlation between emotional and cognitive engagement was as high as 0.84 (Perera et al., 2018a).

\section{Alternative Models}

Since the fit of the initial CFA model to the data was only marginal and discriminant validity was not supported regarding certain factors, alternative models were examined (Kline, 2013; Shek and Yu, 2014). Large value of modification indices for covariances was observed between item one and nine, suggesting an error term can be added between them. These items capture teachers' levels of connection and relationships with their colleagues. Item 15 showed cross-loadings on both emotional and cognitive engagement with the highest MI value (63.69), indicating that this item does not only measure the extent to which teachers devote physical and cognitive resources in

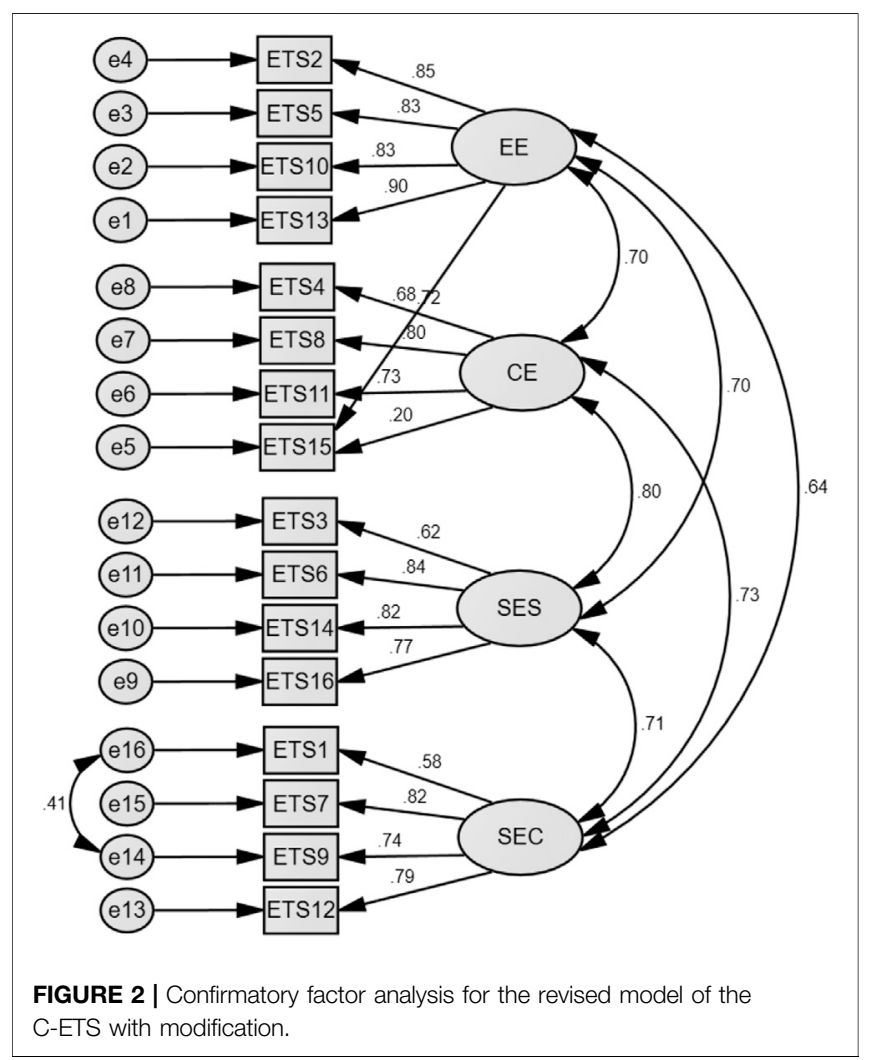




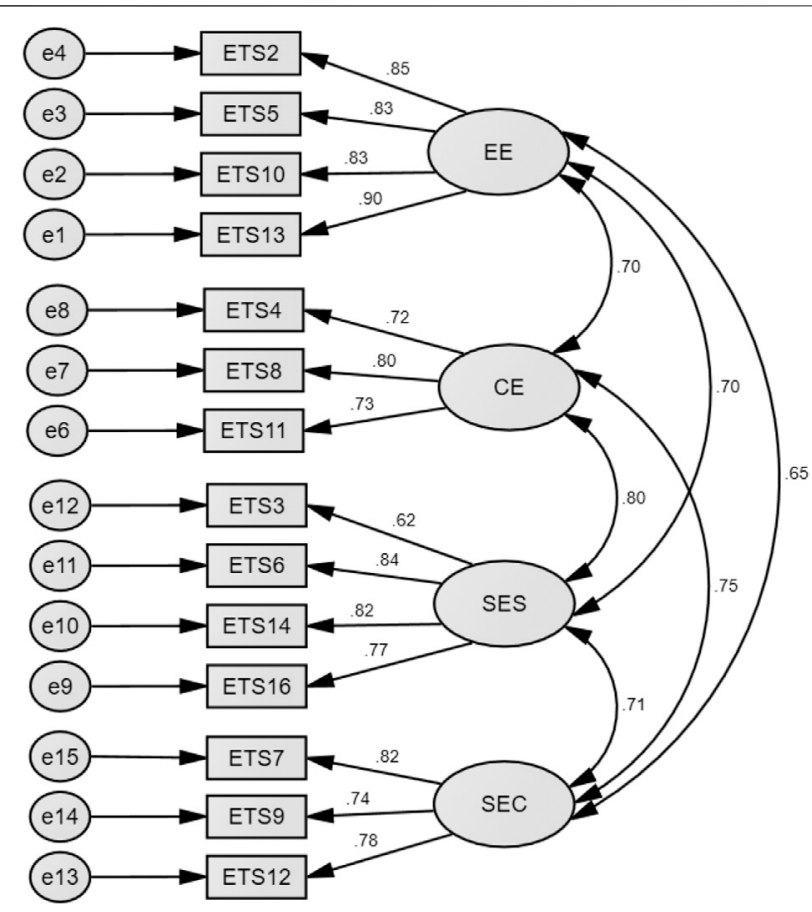

FIGURE 3 | Confirmatory factor analysis for the 14-item model of the C-ETS.

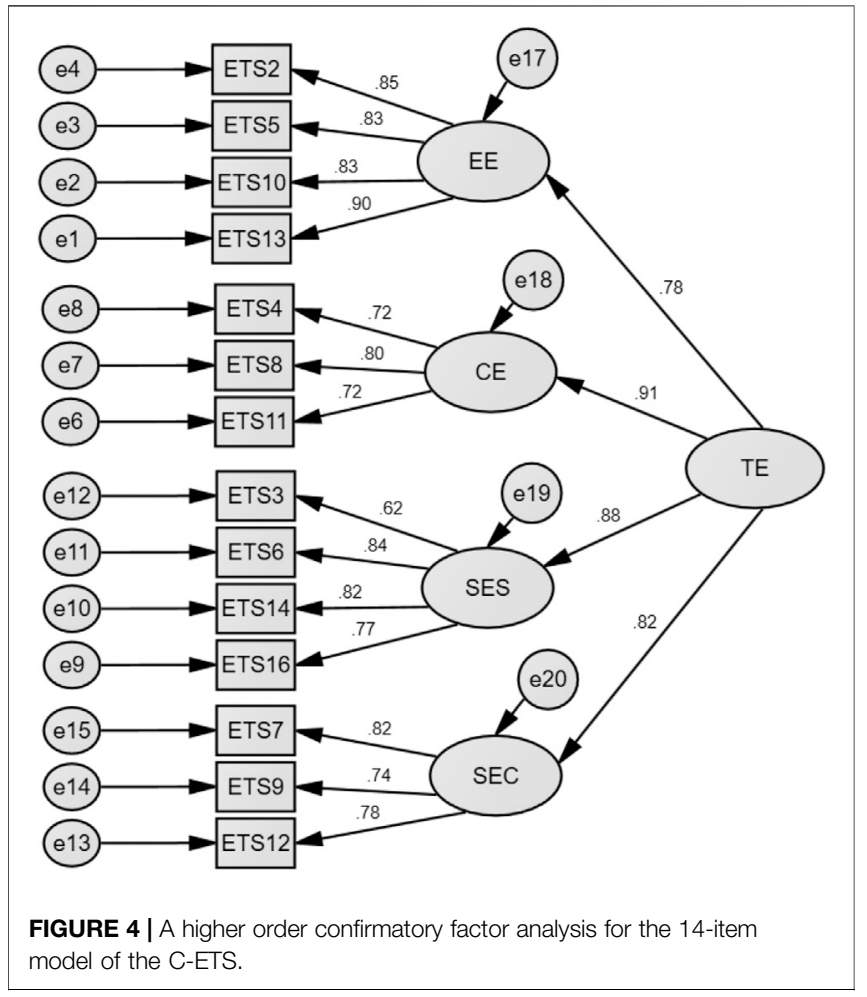

TABLE 2 | Convergent and discriminant validity of the 14-item model of C-ETS.

\begin{tabular}{|c|c|c|c|c|}
\hline & AVE & EE & CE & SES \\
\hline Emotional engagement (EE) & 0.728 & - & & \\
\hline Cognitive engagement (CE) (3 items) & 0.564 & 0.490 & - & \\
\hline Social engagement: students (SES) & 0.589 & 0.490 & 0.640 & - \\
\hline Social engagement: colleagues (SEC) (3 items) & 0.615 & 0.423 & 0.563 & 0.504 \\
\hline
\end{tabular}

Note. $A V E=$ Average variance extracted. Square of the correlations among the four factors of teacher engagement are off-diagonal, ps $<0.001$.

teaching, but also their positive emotional responses to their work. Thus, this item is allowed to also load on emotional engagement. The revised model with modification indicated an acceptable level of fit (Figure 2), with $\chi^{2} / \mathrm{df}=2.81, p<0.001$; $\mathrm{RMSEA}=0.073,90 \% \mathrm{CI}=0.063,0.083$; CFI $=0.95$; NFI $=0.93$; IFI $=0.95$; and TLI $=0.94$. This model was deemed to be a better fit than the initial model because the $\chi^{2}$ difference value was significant $\left(\Delta \chi^{2}[2]=146.78, p<0.001\right)$. The lower Akaike's Information Criterion (AIC) and Expected Cross-Validation Index (ECVI) values for this model provides further support for a better fit to the data than the initial model.

A parsimonious model was also examined by removing items 1 and 15 (Figure 3). Since the pair of items 1 ("At school, I connect well with my colleagues") and 9 ("At school, I value the relationships I build with my colleagues") might overlap in their meanings, the former item was removed because it had a lower factor loading (0.58) than the latter item (0.73). Item 15 ("While teaching, I work with intensity") was also removed because it had a very low loading estimate $(0.20)$ on its designated factor (cognitive engagement) (Figure 2). All fit indices suggested a good fit for the 14-item model $\left(\chi^{2} / \mathrm{df}=2.71, p<0.001\right.$; RMSEA $=0.071,90 \% \mathrm{CI}=0.059,0.083$; $\mathrm{CFI}=0.96$; $\mathrm{NFI}=0.94$; IFI $=$ 0.96 ; and TLI $=0.95) . A \chi^{2}$ difference test indicated a significant improvement in fit for the 14 -item model over the revised model with modification $\left(\Delta \chi^{2}[25]=78.01, p<0.001\right)$. The Akaike's Information Criterion (AIC) and Expected CrossValidation Index (ECVI) values for this 14-item model was also smaller than the revised model with modification, indicating that the former provides a better fit to the data than the latter. Convergent and discriminant validity were also examined between the initial 16-item and the 14-item models (Tables 1, 2). The results indicated that the values of AVE for CE and SEC increased from 0.520 to 0.564 , and from 0.569 to 0.615 respectively, showing that the three items shared a higher proportion of variance in common than the initial four items in measuring the latent constructs of CE and SEC. All the values of AVE were found to be greater than the corresponding square of the correlations among the four factors of C-ETS, except the one between CE and SES $(=0.64)$ indicating that CE and SES were not well distinct from each other (Table 2). 
TABLE 3 | Goodness-of-fit indices and a comparison among the four models.

\begin{tabular}{|c|c|c|c|c|c|c|c|c|c|c|c|c|}
\hline \multirow[b]{2}{*}{ Model } & \multicolumn{3}{|c|}{ Absolute indexes } & \multicolumn{4}{|c|}{ Relative indexes } & \multicolumn{5}{|c|}{ Model comparison } \\
\hline & $\chi^{2}$ & $\chi^{2 / d f}$ & RMSEA & CFI & NFI & IFI & TLI & & $\Delta \chi^{2}$ & $\Delta \mathbf{d f}$ & AIC & ECVI \\
\hline 1 & 416.849 & 4.25 & 0.098 & 0.91 & 0.89 & 0.91 & 0.89 & & $146.78^{\star \star \star}$ & 2 & 524.85 & 1.54 \\
\hline 2 & 270.069 & 2.81 & 0.073 & 0.95 & 0.93 & 0.95 & 0.94 & 2 vs. 1 & $78.01^{\star \star \star}$ & 25 & 382.07 & 1.12 \\
\hline 3 & 192.062 & 2.71 & 0.071 & 0.96 & 0.94 & 0.96 & 0.95 & 3 vs. 2 & $0.47^{\mathrm{ns}}$ & 2 & 288.06 & 0.85 \\
\hline 4 & 192.530 & 2.64 & 0.069 & 0.96 & 0.94 & 0.96 & 0.95 & 4 vs. 3 & & & 284.53 & 0.84 \\
\hline
\end{tabular}

Note. Model 1: Initial 16-item model; Model 2: Revised model with modification; Model 3: 14-item-first-order model; Model 4: Second-order model; ns = non-significant; ${ }^{* * *}$ < 0.001.

Reliabilities coefficients for this 14-item C-ETS were adequate $(0.91,0.79,0.84$, and 0.82 for $\mathrm{EE}, \mathrm{CE}, \mathrm{SES}$, and SEC, respectively).

\section{The Second-Order Factor Model}

Due to insufficient discriminant validity between CE and SES verified in the 14-item-first-order model, a possible second-order factor model was tested. Klassen et al. (2013) and Yerdelen et al. (2018) found that the second-order model with a single superordinate factor (composite teacher engagement: TE) also fitted the ETS data well. Analyzes based on the second-order model were performed using the same procedure in testing the 14-item-first-order model. As shown in Figure 4, the standardized loading estimates of composite teacher engagement on $\mathrm{EE}, \mathrm{CE}$, SES, and SEC were $0.78,0.91,0.88$, and 0.82 respectively. The fit indices of this higher factor model revealed similar results when compared to the 14-item-first-order model, with $\chi^{2} / \mathrm{df}=2.64, p<$ 0.001 ; $\mathrm{RMSEA}=0.069,90 \% \mathrm{CI}=0.058,0.081$; $\mathrm{CFI}=0.96$; $\mathrm{NFI}=$ 0.94 ; IFI $=0.96$; and TLI $=0.95$. The overall alpha of the scale was 93. The 14-item-first-order and the second-order factor models were comparable because a chi-square different test was not significant $\left(\Delta \chi^{2}[2]=0.47, p>0.05\right)$ and the AIC and ECVI values were similar. The results indicated that both models are viable to measure teacher engagement. However, the target coefficient ( $\mathrm{T}$ : ratio of the $\chi^{2}$ values of the first-order model to the $\chi^{2}$ values of the second-order model) showed that a substantial amount of covariation $(192.062 / 192.530=99.76 \%)$ among the first-order factors can be accounted for by the single second-order superordinate factor (TE). According to Marsh and Hocevar (1985), if the target coefficient approaches 1 (i.e., $>0.90$ ), the second-order model can represent the first-order model. In addition to the insufficient discriminant validity between $\mathrm{CE}$ and SES, the more parsimonious second-order factor model for conceptualizing teacher engagement was preferred for future research. A summary of the goodness-of-fit indices and comparison among the four models is shown in Table 3.

\section{DISCUSSION AND CONCLUSION}

In this study we examined the psychometric properties of the translated Engaged Teacher Scale in Chinese (C-ETS) for use among primary and secondary school teachers in Hong Kong. An initial investigation found that the model fit of the 16-item C-ETS was inferior to the counterpart versions in English and Turkish. It illustrates the issue that measurements may not be entirely equivalent across cultures (Bryne and Watkins, 2003). It can be problems to translate items with exact meaning into indigenous language. It may also be problems of items which are less relevant to the Chinese culture from the emic point of view. The results were not very surprising as previous research conducted among Chinese teachers has to refine foreign scales for further analyzes. For example, Yin (2012) found that the wellknown 14-item Emotional Labor Strategy Scale (ELSS) Diefendorff et al. (2005) was not good enough to fit the data when used in a sample of teachers from Beijing. Subsequently the author had to remove one item to improve the model fit. Similarly, two items of the 17-item Teacher Commitment Questionnaire (TCQ) Razak et al. (2010) were deleted because of their very low factor loadings when used in a sample of Chinese tertiary teachers (Han et al., 2016). Removing the two problematic items substantially improved the model fit.

The 16-item C-ETS was modified by deleting item 1 ("At school, I connect well with my colleagues") and item 15 ("While teaching, I work with intensity"). It may be that teachers who value the relationships with colleagues are more willing to devote time and efforts to connect with them. Item 15, as an indicator of cognitive engagement, did not load well on its designated factor, which is in line with the work of Perera et al. (2018a) showing that being emotionally engaged in teaching may also involve cognitive energy. Removing these two items not only improved the model fit of the C-ETS but also enhanced the convergent and discriminant validity for the C-ETS subscales. Neither the efforts of Klassen et al. (2013) in developing the ETS nor a validation study conducted by Yerdelen et al. (2018) provided evidence of discriminant validity of the first-order model. However, discriminant validity problem was still identified between the factors of cognitive engagement and social engagement with students in the modified first-order model, justifying an examination of the second-order model.

With a target coefficient approaching 1, this study provides empirical supports for the second-order factor structure of the C-ETS, indicating that teacher engagement can be represented as a single superordinate construct with four underlying dimensions: (1) emotional engagement, (2) cognitive engagement, (3) social engagement-students, and (4) social engagement-colleagues. Thus, our results lend support to the 14-item-second-order model as a latent construct of an overall teacher engagement.

\section{Contributions and Implications}

This study adds to the literature on teacher engagement by validating a Chinese version of the ETS, making it be potentially applied in the Chinese school context. In a few research studies conducted in China (Li et al., 2015; Han 
et al., 2016; Lu et al., 2018), all of them adopted the UWES in investigating teacher engagement. As previously mentioned, the UWES may fail to reflect the investment of energies of teachers in developing social relationships with students and colleagues. Given that social engagement with students and colleagues are two newly added dimensions of the ETS representing the unique engagement of teachers, they play a critical role in future studies. As teacher engagement in Chinese societies is still underresearched, this area is worth further examination. Using a more contextualized and psychometrically-sound measure (C-ETS) seems promising. To the best of our knowledge, there are only English, Turkish, and Chinese (this study) versions of the ETS. To continue the efforts in exploring teacher engagement across countries, the ETS should be translated in different languages and validated in different contexts, thereby making cross-cultural comparisons possible.

Since the dimensions of teacher engagement fail to distinguish well from one another, subscale modifications are need to improve discriminant validity. More importantly, knowing the levels of these four dimensions of teacher engagement separately would allow researchers to disentangle their differential relationships with various teacher and student attributes and outcomes. For example, teachers who reported higher levels of efficacy to engage students were more likely to show higher levels social engagement with both students and colleagues (Yerdelen et al., 2018), showing that teacher engagement and teacher selfefficacy are not only theoretically related, but their subdimensions have differential relationships with one another.

\section{Limitations and Future Research}

A few limitations need to be noted in this study. First, data were drawn from the same sample instead of different samples in performing a series of CFA, which may limit the generalizability of the results. Second, as a preliminary validation study of the C-ETS, there was no examination of the relationships between teaching engagement and other related variables, which may hinder the convergent, discriminant, and predictive validity of the scale. Third, we did not perform test of invariance between primary and secondary schools, meaning that it is difficult to claim the factor structure of the C-ETS is the same for both levels of school. Fourth, self-reported measure of teacher engagement was adopted, which may be subject to social desirability.

To overcome the above limitations, future research is required for further validation and application of the C-ETS in Chinese teachers with a more representative and larger sample by means of probability sampling technique to ensure generalizability. Moreover, additional research that tests whether the subscale scores of the C-ETS correlate with other theoretically and empirically related constructs will further help establish the utility of the scale for research in Chinese teachers. For

\section{REFERENCES}

Bakker, A. B., and Bal, M. P. (2010). Weekly Work Engagement and Performance: A Study Among Starting Teachers. J. Occup. Organizational Psychol. 83, 189-206. doi:10.1348/096317909x402596 example, a range of theoretically-relevant teaching and learning variables (e.g. teaching effectiveness and student engagement) in relation to teaching engagement should be examined in a longitudinal design so as to ascertain the directional inferences among the variables. In addition, multigroup analysis can be conducted to assess whether the C-ETS structure is equivalent (invariant) in different groups (e.g. primary vs. secondary school teachers). To provide alternative source of information of teacher engagement, student-rating measure such as the Chinese version of the Questionnaire on Teacher Interaction (C-QTI) Sivan et al. (2014) can be included in future research. The C-QTI measures students' perception of their teachers' interpersonal relationships in the classroom which may provide additional information on social engagement with students revealed by the C-ETS.

In conclusion, with the recognition of teacher engagement as critical to understanding teaching and learning outcomes, this study has advanced and validated a Chinese version of the ETS. The present study makes contribution to the literature on teacher engagement by providing preliminary evidence on the psychometric properties of the C-ETS.

\section{DATA AVAILABILITY STATEMENT}

The raw data supporting the conclusion of this article will be made available by the authors, without undue reservation.

\section{ETHICS STATEMENT}

The studies involving human participants were reviewed and approved by the Research Ethics Committee (REC), Hong Kong Baptist University. The patients/participants provided their written informed consent to participate in this study.

\section{AUTHOR CONTRIBUTIONS}

"SK and HC contributed to conception and design of the study. SK and SS organized the database and performed the statistical analysis. SK wrote the first draft of the manuscript. HC, SS, KK, and SL wrote sections of the manuscript. All authors contributed to manuscript revision, read, and approved the submitted version."

\section{FUNDING}

This study was funded by the Faculty Research Grant (FRG2/1617/098), Faculty of Social Sciences, Hong Kong Baptist University.

Bakker, A. B., Schaufeli, W. B., Demerouti, E., and Euwema, M. C. (2007). “An Organisational and Social Psychological Perspective on Burnout and Work Engagement," in The Scope of Social Psychology: Theory and Applications. Editors M. Hewstone, H. A. W. Schut, J. B. E. De Wit, K. Van Den Bos, and M. S. Stroebe (Howe, East Sussex: Psychology Press), $229-252$. 
Bakker, A. B., Schaufeli, W. B., Leiter, M. P., and Taris, T. W. (2008). Work Engagement: An Emerging Concept in Occupational Health Psychology. Work \& Stress 22, 187-200. doi:10.1080/02678370802393649

Barkhuizen, N., Rothmann, S., and van de Vijver, F. J. R. (2013). Burnout and Work Engagement of Academics in Higher Education Institutions: Effects of Dispositional Optimism. Stress Health 30, 322-332. doi:10.1002/smi.2520

Bollen, K. A. (1989). Structural Equations with Latent Variables. New York: Wiley. doi:10.1002/9781118619179

Browne, M. W., and Cudeck, R. (1993). “Alternative Ways of Assessing Model Fit,” in Testing Structural Equation Models. Editors K. A. Bollen, and J. S. Long (Newbury Park, CA: Sage), 136-162.

Bryne, B. M. (2016). Structural Equation Modelling with AMOS: Basic Concepts, Applications and Programming. 3rd ed. New York, NY: Routledge.

Bryne, B. M., and Watkins, D. (2003). The Issue of Measurement Invariance Revisited. J. Cross Cult. Psychol. 34, 155-175. doi:10.1177/ 0022022102250225

Deci, E. L., and Ryan, R. M. (1985). Intrinsic Motivation and Self-Determination in Human Behavior. New York, NY: Plenum. doi:10.1007/978-1-4899-2271-7

Diefendorff, J. M., Croyle, M. H., and Gosserand, R. H. (2005). The Dimensionality and Antecedents of Emotional Labor Strategies. J. Vocational Behav. 66, 339-357. doi:10.1016/j.jvb.2004.02.001

Eldor, L., and Shoshani, A. (2017). Are You Being Served? The Relationship between School Climate for Service and Teachers' Engagement, Satisfaction, and Intention to Leave: A Moderated Mediation Model. J. Psychol. 151, 359-378. doi:10.1080/00223980.2017.1291488

Gagné, M., and Deci, E. L. (2005). Self-determination Theory and Work Motivation. J. Organiz. Behav. 26, 331-362. doi:10.1002/job.322

González-Romá, V., Schaufeli, W. B., Bakker, A. B., and Lloret, S. (2006). Burnout and Work Engagement: Independent Factors or Opposite Poles?. J. Vocational Behav. 68, 165-174. doi:10.1016/j.jvb.2005.01.003

Hair, J. F., Jr., Babin, B. J., Anderson, R. E., and Black, W. C. (2018). Multivariate Data Analysis. 8th ed. Belmont, CA: Wadsworth Cengage Learning.

Hakanen, J. J., Bakker, A. B., and Schaufeli, W. B. (2006). Burnout and Work Engagement Among Teachers. J. Sch. Psychol. 43, 495-513. doi:10.1016/j.jsp. 2005.11.001

Han, J., Yin, H., and Wang, W. (2016). The Effect of Tertiary Teachers' Goal Orientations for Teaching on Their Commitment: the Mediating Role of Teacher Engagement. Educ. Psychol. 36, 526-547. doi:10.1080/01443410.2015.1044943

Høigaard, R., Giske, R., and Sundsli, K. (2012). Newly Qualified Teachers' Work Engagement and Teacher Efficacy Influences on Job Satisfaction, Burnout, and the Intention to Quit. Eur. J. Teach. Edu. 35, 347-357. doi:10.1080/02619768. 2011.633993

Hu, L. T., and Bentler, P. M. (1999). Cutoff Criteria for Fit Indexes in Covariance Structure Analysis: Conventional Criteria versus New Alternatives. Struct. Equation Model. A Multidisciplinary J. 6, 1-55. doi:10.1080/ 10705519909540118

Jackson, L. T. B., Rothmann, S., and van de Vijver, F. J. R. (2006). A Model of Work-Related Well-Being for Educators in South Africa. Stress and Health 22, 263-274. doi:10.1002/smi.1098

Klassen, R. M., Aldhafri, S., Mansfield, C. F., Purwanto, E., Siu, A. F. Y., Wong, M. W., et al. (2012). Teachers' Engagement at Work: An International Validation Study. J. Exp. Edu. 80, 317-337. doi:10.1080/00220973.2012.678409

Klassen, R. M., and Durksen, T. L. (2015). "Recent Advances in Research on Teacher Motivation and Emotions," in The International Handbook of Social Psychology of the Classroom. Editors C. M. Rubie-Davies, J. M. Stephens, and P. Watson (Abingdon, Oxon: Routledge), 339-349.

Klassen, R. M., Yerdelen, S., and Durksen, T. L. (2013). Measuring Teacher Engagement: Development of the Engaged Teachers Scale (ETS). Frontline Learn. Res. 2, 33-52. doi:10.14786/flr.vli2.44

Kline, R. B. (2013). "Exploratory and Confirmatory Factor Analysis," in Applied Quantitative Analysis in the Social Sciences. Editors Y. Petscher, and C. Schatschneider (New York: Routledge), 171-207.

Kline, R. B. (2016). Principles and Practice of Structural Equation Modeling. 4th ed. New York: Guildford.

Li, M., Wang, Z., You, X., and Gao, J. (2015). Value Congruence and Teachers' Work Engagement: The Mediating Role of Autonomous and Controlled Motivation. Personal. Individual Differences 80, 113-118. doi:10.1016/j.paid. 2015.02.021
Lu, M. H., Hao, L., Chen, X. M., and Potměšilc, M. (2018). Teacher Efficacy, Work Engagement, and Social Support Among Chinese Special Education School Teachers. Frontier Psychol. 9, 648. doi:10.3389/fpsyg.2018.00648

Marsh, H. W., and Hocevar, D. (1985). Application of Confirmatory Factor Analysis to the Study of Self-Concept: First- and Higher Order Factor Models and Their Invariance across Groups. Psychol. Bull. 97, 562-582. doi:10.1037/0033-2909.97.3.562

Maslach, C., Leiter, M. P., and Schaufeli, W. B. (2008). "Measuring Burnout," in The Oxford Handbook of Organizational Well-Being. Editors C. L. Coopper, and S. Cartwright (Oxford: Oxford University Press), 86-108.

Maslach, C., Schaufeli, W. B., and Leiter, M. P. (2001). Job Burnout. Annu. Rev. Psychol. 52, 397-422. doi:10.1146/annurev.psych.52.1.397

Meyer, J. P., and Gagnè, M. (2008). Employee Engagement From a SelfDetermination Theory Perspective. Ind. Organ. Psychol. 1, 60-62. doi:10. $1111 / j .1754-9434.2007 .00010 . x$

Perera, H. N., Granziera, H., and Mcllveen, P. (2018a). Profiles of Teacher Personality and Relations with Teacher Self-Efficacy, Work Engagement, and Job Satisfaction. Personal. Individual Differences 120, 171-178. doi:10. 1016/j.paid.2017.08.034

Perera, H. N., Vosicka, L., Granziera, H., and McIlveen, P. (2018b). Towards an Integrative Perspective on the Structure of Teacher Work Engagement. J. Vocational Behav. 108, 28-41. doi:10.1016/j.jvb.2018.05.006

Philipp, A., and Schüpbach, H. (2010). Longitudinal Effects of Emotional Labour on Emotional Exhaustion and Dedication of Teachers. J. Occup. Health Psychol. 15, 494-504. doi:10.1037/a0021046

Razak, N. A., Darmawan, I. G. N., and Keeves, J. P. (2010). The Influence of Culture on Teacher Commitment. Soc. Psychol. Edu. 13, 185-205. doi:10.1007/s11218009-9109-z

Schaufeli, W. B., and Bakker, A. B. (2004). Job Demands, Job Resources, and Their Relationship with Burnout and Engagement: A Multi-Sample Study. J. Organiz. Behav. 25, 293-315. doi:10.1002/job.248

Schaufeli, W. B., Bakker, A. B., and Salanova, M. (2006). The Measurement of Work Engagement with a Short Questionnaire. Educ. Psychol. Meas. 66, 701-716. doi:10.1177/0013164405282471

Schaufeli, W. B., Salanova, M., González-romá, V., and Bakker, A. B. (2002). The Measurement of Engagement and Burnout: A Two Sample Confirmatory Factor Analytic Approach. J. Happiness Stud. 3, 71-92. doi:10.1023/a: 1015630930326

Shek, D. T. L., and Yu, L. (2014). Confirmatory Factor Analysis Using AMOS: a Demonstration. Int. J. Disabil. Hum. Develop. 13, 191-204. doi:10.1515/ijdhd2014-0305

Sivan, A., Chan, D. W. K., and Kwan, Y. W. (2014). Psychometric Evaluation of the Chinese Version of the Questionnaire on Teacher Interaction (C-QTI) in Hong Kong. Psychol. Rep. 114, 823-842. doi:10.2466/08.11.pr0.114k29w9

Skaalvik, E. M., and Skaalvik, S. (2014). Teacher Self-Efficacy and Perceived Autonomy: Relations with Teacher Engagement, Job Satisfaction, and Emotional Exhaustion. Psychol. Rep. 114, 68-77. doi:10.2466/14.02.pr0. $114 \mathrm{k} 14 \mathrm{w} 0$

Timms, C., Graham, D., and Cottrell, D. (2007). "I Just Want to Teach". J. Educ. Admin 45, 569-586. doi:10.1108/09578230710778204

Yerdelen, S., Durksen, T., and Klassen, R. M. (2018). An International Validation of the Engaged Teacher Scale. Teach. Teach. 24, 673-689. doi:10.1080/13540602. 2018.1457024

Yin, H. (2012). Adaptation and Validation of the Teacher Emotional Labour Strategy Scale in China. Educ. Psychol. 32, 451-465. doi:10.1080/01443410. 2012.674488

Conflict of Interest: The authors declare that the research was conducted in the absence of any commercial or financial relationships that could be construed as a potential conflict of interest.

Copyright $\odot 2021$ Ho, Chan, Chan, Fung and Hung. This is an open-access article distributed under the terms of the Creative Commons Attribution License (CC BY). The use, distribution or reproduction in other forums is permitted, provided the original author(s) and the copyright owner(s) are credited and that the original publication in this journal is cited, in accordance with accepted academic practice. No use, distribution or reproduction is permitted which does not comply with these terms. 